\title{
Deaths from cardiovascular disease involving anticoagulants: a systematic synthesis of coroners' case reports
}

Ali Anis (0000-0003-4680-4541), medical student ${ }^{1}$;

Carl Heneghan (0000-0002-1009-1992), DPhil, Director ${ }^{2}$ and Co-Director ${ }^{3}$;

Jeffrey K. Aronson (0000-0003-1139-655X), DPhil, Clinical Pharmacologist ${ }^{2}$;

Nicholas J. DeVito (0000-0001-8286-1995), MPH, doctoral researcher ${ }^{4}$;

Georgia C. Richards* (0000-0003-0244-5620), BSc (Hons I), Honorary Researcher ${ }^{2}$ and

Post-Doctoral Research Fellow ${ }^{3}$.

${ }^{1}$ Oxford University Medical School, John Radcliffe Hospital, Headington, University of

Oxford, Oxford, OX3 9DU, UK.

${ }^{2}$ Centre for Evidence-Based Medicine, Nuffield Department of Primary Care Health

Sciences, University of Oxford, Radcliffe Observatory Quarter, Woodstock Road, Oxford, OX2 6GG, UK.

${ }^{3}$ Global Centre on Healthcare and Urbanisation, Kellogg College, University of Oxford, 6062 Banbury Road, Oxford, OX2 6PN, UK.

${ }^{4}$ EBM Datalab, Nuffield Department of Primary Care Health Sciences, University of Oxford, Radcliffe Observatory Quarter, Woodstock Road, Oxford, OX2 6GG, UK.

*Corresponding author: Georgia C. Richards; Global Centre on Healthcare and Urbanisation, Kellogg College, University of Oxford, 60-62 Banbury Road, Oxford, OX2 6PN, UK; email: georgia.richards@kellogg.ox.ac.uk; phone: +44 7902410 774; twitter: @Richards_G_C

Word count: 2571 
medRxiv preprint doi: https://doi.org/10.1101/2021.04.28.21256272; this version posted August 19, 2021. The copyright holder for this preprint (which was not certified by peer review) is the author/funder, who has granted medRxiv a license to display the preprint in perpetuity.

It is made available under a CC-BY-NC-ND 4.0 International license .

\begin{abstract}
Background: The global burden of cardiovascular disease (CVD) is forecast to increase, and anticoagulants will remain important medicines for its management. Coroners' Prevention of Future Death reports (PFDs) provide valuable insights that may enable safer and more effective use of these agents.
\end{abstract}

Aim: To identify CVD-related PFDs involving anticoagulants.

Design and Setting: Retrospective observational study of coronial case reports in England and Wales between 2013 and 2019.

Method: We screened 3037 PFDs for eligibility and included PFDs where CVD and an anticoagulant caused or contributed to the death. We descriptively analysed included cases and used content analysis to assess concerns raised by coroners and who responded to them.

Results: We identified 113 cardiovascular disease-related PFDs involving anticoagulants. Warfarin $(36 \%)$, enoxaparin $(11 \%)$, and rivaroxaban $(11 \%)$ were the most common anticoagulants reported. Concerns most frequently raised by coroners included poor systems (31\%), poor communication (25\%), and failures to keep accurate medical records $(25 \%)$. These concerns were most often directed to NHS trusts (29\%), hospitals (10\%), and general practices $(8 \%)$. Nearly two-thirds $(60 \%)$ of PFDs had not received responses from such organisations, which are mandatory under regulation 28 of the Coroners' (Investigations) Regulations 2013. We created a publicly available tool, https://preventabledeathstracker.net/, which displays coroners' reports in England and Wales to streamline access and identify important lessons to prevent future deaths.

Conclusion: National organisations, healthcare professionals, and prescribers should take actions to address the concerns of coroners' in PFDs to improve the safe use of anticoagulants in patients with cardiovascular disease.

Keywords: cardiovascular diseases, anticoagulants, inappropriate prescribing, medication errors, premature mortality, coroners and medical examiners 


\section{How this fits in}

A previous assessment of 500 PFDs identified anticoagulants as the class of drugs most often involved in fatal medication errors. This study uses innovative methods to automatically collect all available PFDs between 2013 and 2019 to identify deaths from cardiovascular disease when the use of or lack of anticoagulants caused or contributed to the death. Coroners' raised hundreds of coroners in their reports, including issues with communication, following protocols, education and training, access to resources, and safety. Despite repeat concerns with national relevance being identified, most CVD-anticoagulant PFDs were sent locally to NHS Trusts, hospitals, and general practices, limiting their ability to reduce harms and prevent premature deaths. 
medRxiv preprint doi: https://doi.org/10.1101/2021.04.28.21256272; this version posted August 19, 2021. The copyright holder for this preprint

\section{Introduction}

Cardiovascular disease (CVD) is the leading cause of mortality worldwide $(1,2)$. In 2019, 18.6 million deaths (33\% of all deaths) were due to CVD (3), with a projection of 24 million annual deaths by 2030 (4). In England and Wales, CVD was responsible for almost a quarter of all deaths in 2019 (5,6). Premature mortality from CVD in England has also been attributed to greater socioeconomic inequalities in people under 75 years of age (7).

In patients at high risk of strokes, heart attacks, deep vein thrombosis, or pulmonary embolism, anticoagulation is one possible prophylactic intervention (8). Anticoagulants target different points of the coagulation cascade, helping to prevent blood clot formation and the adverse effects of excessive clotting. In English primary care, the prescribing of anticoagulants increased from 15 million doses to 33 million between January 2014 and August 2019 (9). Three main types of anticoagulants are outlined in guidance published by The National Institute for Health and Care Excellence (NICE): low molecular weight heparin (e.g. enoxaparin), vitamin $\mathrm{K}$ antagonists (e.g. warfarin), and direct-acting oral anticoagulants (DOACs; e.g. rivaroxaban). The effectiveness of anticoagulants for cardiovascular disease is well established. For example, adjusted-dose warfarin reduced stroke by $62 \%$ (95\% CI: 48\% to $72 \%$ ) in patients with atrial fibrillation (10). However, the narrow therapeutic index and frequent laboratory monitoring needed with warfarin administration have led to the development of DOACs (11). Bleeding associated with warfarin therapy is among the top three adverse drug reactions that cause hospital admissions in England (12).

Coroners' reports, previously named Rule 43 and now called Prevention of Future Death reports (PFDs), are written when the coroner believes that action is necessary to prevent a death (13). PFDs are sent to specific individuals or organisations, who, under regulation 28 and 29 of the Coroners (Investigations) Regulations 2013, have a duty to respond within 56 days of the date of report (14). Previous analysis of coroners' reports has shown that anticoagulants were the drugs most commonly reported to have been involved in fatal medication errors in England and Wales $(15,16)$. This analysis also found that coroners' most commonly raised concerns regarding adverse drug reactions to prescribed medicines, followed by omissions of necessary treatment and monitoring failures. In this study, the authors examined only a proportion $(n=500)$ of all published coroners' reports. Building on previous research $(15,16)$, we aimed to assess all available PFDs between 2013 ad 2019 for 
medRxiv preprint doi: https://doi.org/10.1101/2021.04.28.21256272; this version posted August 19, 2021. The copyright holder for this preprint

deaths that involved individuals with CVD, in whom the use or lack of use of anticoagulants caused or contributed to the death. We sought to discover: 1) what concerns were highlighted by coroners; 2) to which individuals or organizations PFDs were addressed; 3) whether responses were made by the individuals or organizations to whom the PFDs were sent.

\section{Methods}

We designed a retrospective observational study and preregistered our study protocol on an open repository (17). We used the STROBE reporting guideline to write our manuscript.

\section{Data collection}

PFDs are openly available on the Courts and Tribunals Judiciary website (18). We used web scraping to automatically collect PFDs, and from the output created the Preventable Deaths Database and the Preventable Deaths Tracker: https://preventabledeathstracker.net/ (19). The code to create the scraper is openly available on GitHub (20) and has been previously described (21). The Preventable Deaths Database contains: the case reference number; the date of the report; the name of the deceased; the coroner's name; the coroner's jurisdiction; the category of death (defined by the Chief Coroners' office); to whom the report was sent; and the URL to the Judiciary website. For population data on deaths from CVD, we used the most recent (2001-2019) dataset of deaths registered in England and Wales, released by the Office for National Statistics in 2020 (ONS) (5).

\section{Eligibility of cases}

We examined all cases $(n=3037)$ in the Preventable Deaths Database from July 2013 (the first date on which they were uploaded to the Judiciary website) to December 2019. We screened the cases independently in duplicate (AA \& GCR) to determine whether CVD caused or contributed to the death using a pre-defined algorithm (Supplementary Figure 1). We used Chapter IX (Diseases of the Circulatory System) of the International Statistical Classification of Diseases and Related Health Problems 10th Revision (ICD-10) to align with the ONS classifications of death. When the deceased suffered from a single condition listed under chapter IX that could not be unequivocally attributed to external causes, the case was included. We then screened for cases where one or more anticoagulant caused or contributed to the death or where the coroner suggested that had an anticoagulant been given, it would have prevented the death. We defined anticoagulants as agents targeting different points of 
the coagulation pathway to prevent clot formation. Discrepancies were resolved by consensus discussion (AA, GCR, \& JKA).

\section{Data extraction}

For included cases, one study author (AA) manually extracted the following variables into a predesigned Google Sheet, which was cross examined by another study author (GCR): the individuals or organizations to whom reports were sent, who responded, the due date of response and the date received; date of death; the dates on which the inquest started and ended; age; sex; setting or location of death; medical cause(s) of death; the coroner's conclusion(s) of the inquest; relevant medical, mental health, and social history; whether any substance(s) were implicated in the death and the type of substance(s); coroner's concern(s) and actions proposed by the coroner.

\section{Data analysis}

To determine the annual deaths from CVD in England and Wales, we filtered the ONS data (5) for deaths caused by conditions listed under chapter IX of ICD-10 (ICD-10 codes: I00I99). We summed the number of reports written each year and compared the totals with ONS mortality data for CVD. We used descriptive statistics to report the quantitative findings and performed content analysis (22) to classify the concerns and actions raised by coroners with categories derived inductively. We calculated a response rate for each organisation as the proportion of reports to which a response was submitted over the total number received. Responses were further classified as either on-time (delivered within 56 days), late (submitted after 56 days), or overdue (when no response was found on the Judiciary website). A response rate of $100 \%$ means that individual or organisation adhered to regulation 28 of the Coroners' (Investigations) Regulations 2013 and responded to all PFDs issued by coroners.

\section{Software and data sharing}

We used Python v3.7 in Jupyter Notebooks with pandas, seaborn, and matplotlib libraries to analyse the data and create figures. The data, statistical code, and study materials are openly available via the Open Science Frame (23) and GitHub (24). 
medRxiv preprint doi: https://doi.org/10.1101/2021.04.28.21256272; this version posted August 19, 2021. The copyright holder for this preprint

\section{Results}

In 659 cases (22\% of all PFDs) CVD caused or contributed to the death (Figure 1). Of the CVD-related PFDs, 17\% ( $\mathrm{n}=113)$ involved or mentioned the use or lack of an anticoagulant. Over the seven-year study period, there was a median of 16 (IQR: 15-17) CVD-related anticoagulant PFDs each year (Supplementary Table 1).

In 99 cases, an anticoagulant caused or contributed to the death. Warfarin (36\%) was the most common anticoagulant specified, followed by enoxaparin $(11 \%)$ and rivaroxaban $(11 \%)$ (Figure 2). In 14 cases, the coroner mentioned that the administration of an anticoagulant might have prevented the death (Figure 2). There were equal proportions of males $(n=56)$ and females $(\mathrm{n}=57)$ in the 113 cases. The median age of the deceased were 76 years (IQR: 61-84 years; $\mathrm{n}=77$ ).

Seventy-five coroners across 36 jurisdictions wrote 113 PFDs. Coroners in the North West $(25 \%)$ and South East (19\%) of England wrote the most, whereas those in the East (2\%) and North East (3\%) of England wrote very few (Table 1).

We identified 335 individual concerns raised by coroners in the 113 cases. Using content analysis, we categorised these concerns into 51 groups and five higher-order themes, including communication, failure to follow protocols, education and training, resources, and safety (Table 2). The most common concerns were poor systems (31\%), poor communication (25\%), failure to keep accurate medical records (25\%), and failures or delays in having appropriate assessments done (17\%). Concerns most frequently belonged to the theme of following protocols (36\%), followed by communication (22\%), and safety issues (21\%).

In $82 \%$ of CVD-related PFDs involving anticoagulants, coroners stated that "action should be taken" (Supplementary Table 2). When coroners suggested further actions, we grouped their actions into 28 categories. Ensuring effective communication (3\%), introducing new policies and protocols (2\%), and reviewing the handling of prescriptions (2\%) were the most common actions proposed (Supplementary Table 2).

For the 113 CVD-related PFDs involving anticoagulants, coroners sent 181 reports to 37 individuals and organisations (Table 3). Local services such as NHS Trusts (29\%), hospitals 
medRxiv preprint doi: https://doi.org/10.1101/2021.04.28.21256272; this version posted August 19, 2021. The copyright holder for this preprint

(10\%), and general practices (8\%), were addressed PFDs most frequently. By statute addressees must respond to the coroner within 56-days, but only $29 \%$ responded on time; $11 \%$ responded late and $60 \%$ were overdue. Medical societies $(0 \%)$ and royal colleges $(0 \%)$ had the lowest response rates, while NHS entities had the highest, albeit with half of their responses overdue. Ranking recipients by response rate and response time, NHS 111, NHS Wales, and CCGs performed best (Supplementary Table 3).

\section{Discussion}

\section{Summary}

We identified 113 premature deaths from cardiovascular disease involving anticoagulants. In $88 \%$ of cases, the use of one or more anticoagulant resulted in death. In $12 \%$ of cases, the administration of an anticoagulant may have prevented death. We found wide geographical variation in the issuing of PFDs and the type of information reported, with coroners in Greater Manchester writing the most. Coroners raised hundreds of concerns, some relating directly to the risks of anticoagulation and the caution with which patients on these drugs should be managed, though rarely were the concerns not already mentioned in guidance available to healthcare professionals. Most of these concerns were addressed locally and under regulation 28, 109 individuals or organisations were overdue in their response to coroners.

\section{Strengths and limitations}

We used a reproducible data-collection method to examine all available PFDs from inception to 2019 , which provided an estimated 40-fold time saving (21), and reduced the potential for selection bias. However, the PFDs included in our study depend on the working practices of coroners and the Chief Coroner's Office in uploading PFDs and their responses to the website. The 113 PFDs cannot therefore represent all preventable deaths from CVD involving anticoagulants in England and Wales. There were also missing data; for example, $32 \%$ of PFDs did not report age and $16 \%$ did not specify the type of anticoagulant; this may be attributed to lack of PFD training provided to coroners. Our findings are also limited by the available data and information provided by coroners in PFDs, thus it is not possible to examine the relationship between cardiovascular disease and anticoagulants in causing death, or to differeintiate between the appropriate use, misuse, and underuse of anticoagultants. 
medRxiv preprint doi: https://doi.org/10.1101/2021.04.28.21256272; this version posted August 19, 2021. The copyright holder for this preprint

\section{Comparison with existing literature}

Our study builds on prior research that evaluated smaller samples of coroners' reports $(15,16,25-27)$. Compared with previous studies $(26,28)$, we did not identify a sex imbalance. However, we found that new hazards were rarely identified and that most PFDs were addressed locally, as shown by Ferner et al. (15), which means that valuable lessons were not widely disseminated and may be why we found that coroners repeatedly expressed similar concerns, in line with former research (25). This questions whether PFDs are fulfilling their purpose. Similar to Fox and Jacobson (26), we found pronounced geographical variation in the issuing of PFDs and poor response rates. A review of the coronial system in England and Wales highlighted a lack of accountability, leadership, and quality assurance (29). Since there is no system in place for enforcing or auditing compliance with regulation 28 or assessing the quality of PFDs and the adequacy of responses and actions taken to prevent deaths, our findings show that the system has scope for improvement.

General practices were sent the third highest number of CVD-related PFDs involving anticoagulants, but collectively only $36 \%$ responded. This may be because of a lack of awareness of the statutory requirements and medico-legal training of GPs, as identified by previous research (30). During the COVID-19 pandemic, GPs called for deaths of colleagues to be reported to the coroner and PFDs to be issued (31). Fortunately, the value of PFDs as a tool for improving clinical practice is being recognised, and efforts are underway to widely disseminate their lessons to healthcare professionals, policymakers, and the public (32-37).

\section{Implications for research and/or practice}

Concerns raised by coroners provide lessons for prescribers and policymakers on the safety and proper use of therapies. During the COVID-19 pandemic, patients were switched from warfarin to other oral anticoagulants, given the need for less frequent blood testing (38). Drugs such as andexanet alfa could prove critical in the outcome of patients with severe bleeding during treatment with apixaban or rivaroxaban. Since the coroner expressed concerns (Case: 2018-0032), NICE has drafted an appraisal for andexanet alfa (39), and its publication is expected on 12 May 2021 (40). There has also been a phased launch of andexanet alfa in UK hospitals (41). However, it is unclear whether this was a direct result of the PFD, since no response from the MHRA was published on the Judiciary website. 
When PFDs are addressed to the appropriate recipients at the national level, their actions can help prevent deaths. For example, a PFD was sent to NICE when the deceased suffered a fall while taking an anticoagulant without having the appropriate neuroimaging performed (Case: 2019-0106). The coroner's concerns were acknowledged in a NICE surveillance report (42) and resulted in updating of the NICE guideline on head injury, to emphasise that people taking DOACs should be investigated with the same care as those taking warfarin (43). However, we also identified unaddressed concerns about national guideline; three-quarters of PFDs sent to NICE have no responses listed on the Judiciary website. Restarting warfarin after a head injury is particularly important, as delays could leave the patient at risk of a stroke, but resuming too soon may lead to haemorrhage. A retrospective review of the medical charts of 256 patients admitted to a trauma centre in West Texas between 2009 and 2012 showed that patients who resumed anticoagulant therapy at 7-10 days after the injury had the best prognosis (44). PFDs can therefore be used to update guidance and inform future prospective cohort studies.

Our study provides a database and resource (https://preventabledeathstracker.net/) for future evaluations of PFDs. Further content analysis should be used to assess the 181 responses to the 113 PFDs, to assess the adequacy of actions proposed to prevent deaths and their implementation. Future research could use our open data to examine coroners' concerns in the 546 CVD-related PFDs not involving anticoagulants and their responses. In building the web scraper to collect PFDs, we found various inconsistencies and omissions on the Judiciary website, which should be addressed to improve the quality of data. The missing data from PFDs we have highlighted reveal target areas for coronial training in the writing of PFDs.

\section{Conclusions}

This study used sophisticated, reproducible, and internationally recognised data-collection methods (21) to demonstrate that PFDs provide valuable lessons when prescribing anticoagulants and managing patients with CVD. However, it is unclear whether actions are being taken to incorporate such lessons. To improve patient safety, lessons should be widely disseminated and used in practice. 
medRxiv preprint doi: https://doi.org/10.1101/2021.04.28.21256272; this version posted August 19, 2021. The copyright holder for this preprint

Funding: No funding was obtained to undertake this study.

Ethical approval: As the case reports are publicly available on the Judiciary website, approval from an ethics committee was not required.

Competing interests: AA has no competing interest to disclose. $\mathrm{CH}$ is a National Institute for Health Research (NIHR) Senior Investigator and has received expenses and fees for his media work, received expenses from the World Health Organisation (WHO), Food and Drug Administration (FDA), and holds grant funding from the NIHR School for Primary Care Research (SPCR), and the NIHR SPCR Evidence Synthesis Working Group [Project 380], the NIHR BRC Oxford and the WHO. On occasion, $\mathrm{CH}$ receives expenses for teaching EBM and is also paid for his GP work in NHS out of hours (contract with Oxford Health NHS Foundation Trust). $\mathrm{CH}$ is the Director of the CEBM. JKA has published articles and edited textbooks on adverse drug reactions and interactions and has often given medicolegal advice, including appearances as an expert witness in coroners' courts, dealing with the adverse effects of drugs. NJD has no conflicts related to the submitted work. Outside the submitted work, he declares a doctoral studentship from the Naji Foundation, grant funding from the Fetzer Franklin Memorial Fund, and employment on grants from the Laura and John Arnold Foundation, The Good Thinking Society, and the German Federal Ministry of Education and Research (BMBF). GCR was financially supported by the NIHR SPCR, the Naji Foundation, and the Rotary Foundation to study for a Doctor of Philosophy (2017-2020) but no longer has any financial COIs. GCR is an Associate Editor of BMJ Evidence Based Medicine. The views expressed are those of the authors and not necessarily those of the NHS, the NIHR, or the Department of Health and Social Care.

Acknowledgements and contributions: AA proposed the topic for research, contributed to the protocol and devised the algorithm for the eligibility of cases, screened the database for eligible case reports, extracted and analysed the data, and wrote the first draft of the manuscript. GCR designed the study, wrote the protocol, sourced the data, contributed to the web scraper, provided data management, dual screened the database for eligible cases, analysed the data, provided primary supervisory support and substantiality contributed to subsequent manuscript drafts. JKA and $\mathrm{CH}$ reviewed the protocol and preliminary findings and provided supervisory support. NJD wrote the code and advised on the web scraper. All 
authors have full access to all the data in the study, read and approved the final manuscript, and accept responsibility to submit for publication.

Data availability: Study materials, protocol, data, and statistical code are openly available on the OSF (https://osf.io/qkfjp/) and GitHub (https://github.com/georgiarichards/CVD_anticoags). 


\section{References}

1. Cardiovascular diseases (CVDs). who.int. 2017. Available from: https://www.who.int/news-room/fact-sheets/detail/cardiovascular-diseases-(cvds)

2. CVD risk assessment and management. NICE. 2019. Available from: https://cks.nice.org.uk/topics/cvd-risk-assessment-management/

3. GBD Results Tool. Global Health Data Exchange. 2020. Available from: http://ghdx.healthdata.org/gbd-results-tool

4. The Future of CVD. who.int. Available from: https://www.who.int/cardiovascular_diseases/en/cvd_atlas_25_future.pdf?ua=1

5. Deaths registered in England and Wales - 21st century mortality. Office for National $\begin{array}{llll}\text { Statistics. } & 2020 . & \text { Available }\end{array}$ https://www.ons.gov.uk/peoplepopulationandcommunity/birthsdeathsandmarriages/de aths/datasets/the21stcenturymortalityfilesdeathsdataset

6. ICD-10 Version:2019. who.int. 2019. Available from: https://icd.who.int/browse10/2019/en\#/IX

7. Lewer D, Jayatunga W, Aldridge RW, et al. Articles Premature mortality attributable to socioeconomic inequality in England between 2003 and 2018: an observational study. Lancet Public Health. 2020;5:e33-41.

8. Anticoagulants, including direct-acting oral anticoagulants (DOACs). NICE. 2016. Available from: https://www.nice.org.uk/advice/ktt16/resources/anticoagulantsincluding-directacting-oral-anticoagulants-doacs-pdf-58757956094149

9. Ho KH, Van Hove M, Leng G. Trends in anticoagulant prescribing: A review of local policies in English primary care. Vol. 20, BMC Health Serv Res. BioMed Central Ltd.; 2020.

10. Hart RG, Benavente $\mathrm{O}, \mathrm{McBride} \mathrm{R}$, et al. Antithrombotic therapy to prevent stroke in patients with atrial fibrillation: A meta-analysis. Ann Intern Med. 1999 Oct 5;131(7):492-501.

11. Harter K, Levine M, Henderson SO. Anticoagulation drug therapy: A review. West J Emerg Med. 2015;16(1):11-7.

12. Pirmohamed M, James S, Meakin S, et al. Adverse drug reactions as cause of admission to hospital: Prospective analysis of 18820 patients. BMJ. $2004 \mathrm{Jul}$ 
$3 ; 329(7456): 15-9$.

13. Coroners and Justice Act 2009. legislation.gov.uk. 2009. Available from: https://www.legislation.gov.uk/ukpga/2009/25/pdfs/ukpga_20090025_en.pdf

14. The Coroners (Investigations) Regulations 2013. legislation.gov.uk. 2013. Available from: https://www.legislation.gov.uk/uksi/2013/1629/pdfs/uksi_20131629_en.pdf

15. Ferner RE, Easton C, Cox AR. Deaths from Medicines: A Systematic Analysis of Coroners' Reports to Prevent Future Deaths. Drug Saf. 2018;41(1):103-10.

16. Ferner RE, Ahmad T, Babatunde Z, et al. Preventing Future Deaths from Medicines: Responses to Coroners' Concerns in England and Wales. Drug Saf. 2019 Mar 7;42(3):445-51.

17. Deaths from cardiovascular disease: A systematic analysis of coroners' reports to prevent future deaths in England and Wales. OSF Registries. Available from: https://osf.io/rvw43

18. Prevention of Future Deaths. Courts and Tribunals Judiciary. Available from: https://www.judiciary.uk/subject/prevention-of-future-deaths/

19. Preventable Deaths Tracker. Available from: https://preventabledeathstracker.net/

20. GitHub - georgiarichards/georgiarichards.github.io. Available from: https://github.com/georgiarichards/georgiarichards.github.io

21. DeVito NJ, Richards GC, Inglesby P. How we learnt to stop worrying and love web scraping. Nature. 2020 Sep 1;585(7826):621-2.

22. Kleinheksel AJ, Rockich-Winston N, Tawfik H, et al. Demystifying content analysis. Am J Pharm Educ. 2020 Jan 1;84(1):127-37.

23. Deaths from cardiovascular disease: A systematic analysis of coroners' reports to prevent future deaths in England and Wales. OSF. Available from: https://osf.io/qkfjp/

24. GitHub - georgiarichards/CVD_anticoags. Available from: https://github.com/georgiarichards/CVD_anticoags

25. Leary A, Bushe D, Oldman C, et al. A thematic analysis of the prevention of future deaths reports in healthcare from HM coroners in England and Wales 2016-2019. J Patient Saf Risk Manag. 2021 Feb 3;26(1):14-21.

26. Fox AW, Jacobson J. How well do Regulation 28 reports serve future public health 
medRxiv preprint doi: https://doi.org/10.1101/2021.04.28.21256272; this version posted August 19, 2021. The copyright holder for this preprint

and safety? Med Sci Law. 2021;

27. Holden J, O’Donnell S, Brindley J, et al. Analysis of 1263 deaths in four general practices. Br J Gen Pract. 1998;48(432).

28. Mclean M, Roach J, Armitage R. Local variations in reporting deaths to the coroner in England and Wales: A postcode lottery? J Clin Pathol. 2013 Nov;66(11):933-6.

29. Berry C, Heaton-Armstrong A. A review of the coroner system in England and Wales: A commentary. Vol. 5, Clin Med (London). Royal College of Physicians; 2005. p. 455-9.

30. Start RD, Usherwood TP, Carter N, et al. General practitioner's knowledge of when to refer deaths to a coroner. Br J Gen Pract. 1995;45(393).

31. Kendrick D, Agius R, McKee M, et al. Covid-19: Learning lessons from the deaths of our colleagues. BJGP Life. 2020. Available from: https://bjgplife.com/2020/05/18/gpdeaths/

32. Richards GC, Aronson JK, Heneghan C. Coroners' concerns to prevent harms: A series of coroners' case reports to serve patient safety and educate the public, clinicians and policy-makers. BMJ Evid Based Med. BMJ Publishing Group; 2020.

33. Richards GC. Alcohol-based hand sanitisers: A warning to mitigate future poisonings and deaths. BMJ Evid Based Med. 2020 Apr 1;26(2):65-8.

34. Bilip MK, Richards GC. Emollients and smoking: a fire hazard that could be prevented to reduce future deaths. BMJ Evid Based Med. 2021 Apr 9;0:bmjebm-2020-111648.

35. Thomas ET, Richards GC. Diclofenac in adolescents: Diagnosing and treating gastrointestinal adverse drug reactions can prevent future deaths. BMJ Evid Based Med. 2020 Feb 10;

36. Cox AR, Ferner R. Tramadol: Repeated prescriptions and repeated warnings. BMJ Evid Based Medicine. BMJ Publishing Group; 2021.

37. Swift B, Heneghan C, Aronson JK, et al. Preventable deaths from SARS-CoV-2 in England and Wales: a systematic analysis of coroners' case reports from the COVID19 pandemic. medRxiv. 2021 Jul 23;2021.07.15.21260589.

38. Curtis HJ, MacKenna B, Walker AJ, et al. OpenSAFELY: impact of national guidance on switching from warfarin to direct oral anticoagulants (DOACs) in early phase of COVID-19 pandemic in England. medRxiv. 2020 Dec 4;2020.12.03.20243535. 
39. Single Technology Appraisal (STA): Andexanet alfa for reversing anticoagulation [ID1101]. NICE. 2019. Available from: https://www.nice.org.uk/guidance/gidta10440/documents/scope-consultation-comments-and-responses

40. Andexanet alfa for reversing anticoagulation [ID1101]. NICE. 2020. Available from: https://www.nice.org.uk/guidance/indevelopment/gid-ta10440

41. Andexanet alfa. Specialist Pharmacy Service. 2020. Available from: https://www.sps.nhs.uk/medicines/andexanet-alfa/

42. 2019 surveillance of head injury: assessment and early management (NICE guideline CG176). 2019. NICE. Available from: https://www.nice.org.uk/guidance/cg176/resources/2019-surveillance-of-head-injuryassessment-and-early-management-nice-guideline-cg176-pdf-8944653877477

43. Head injury: assessment and early management. NICE. 2019. Available from: https://www.nice.org.uk/guidance/cg176/chapter/1-Recommendations\#investigatingclinically-important-brain-injuries

44. Puckett Y, Zhang K, Blasingame J, et al. Safest Time to Resume Oral Anticoagulation in Patients with Traumatic Brain Injury. Cureus. 2018 Jul 3;10(7). 
medRxiv preprint doi: https://doi.org/10.1101/2021.04.28.21256272; this version posted August 19, 2021. The copyright holder for this preprint (which was not certified by peer review) is the author/funder, who has granted medRxiv a license to display the preprint in perpetuity.

It is made available under a CC-BY-NC-ND 4.0 International license.

Table 1: Jurisdictions of coroners who issued the 113 Prevent Future Death reports involving an anticoagulant and cardiovascular disease

\begin{tabular}{|c|c|}
\hline Region & No. of cases (\%) \\
\hline North West England & $28(25)$ \\
\hline Greater Manchester & $20(18)$ \\
\hline Blackpool \& Fylde & $4(4)$ \\
\hline Blackburn, Hyndburn \& Ribble Valley & $3(3)$ \\
\hline Cumbria & $1(1)$ \\
\hline South East England & $21(19)$ \\
\hline Surrey & $4(4)$ \\
\hline Kent & $3(3)$ \\
\hline Milton Keynes & $3(3)$ \\
\hline Portsmouth \& South East Hampshire & $3(3)$ \\
\hline West Sussex & $3(3)$ \\
\hline Buckinghamshire & $2(2)$ \\
\hline Berkshire & $1(1)$ \\
\hline Isle of Wight & $1(1)$ \\
\hline Oxfordshire & $1(1)$ \\
\hline Wales & $15(13)$ \\
\hline Powys, Bridgend \& Glamorgan Valleys & $6(5)$ \\
\hline North Wales & $2(2)$ \\
\hline South Wales & $2(2)$ \\
\hline Swansea & $2(2)$ \\
\hline Cardiff \& Vale of Glamorgan & $1(1)$ \\
\hline Carmarthenshire \& Pembrokeshire & $1(1)$ \\
\hline Gwent & $1(1)$ \\
\hline London & $10(9)$ \\
\hline West Midlands & $13(12)$ \\
\hline Black Country & $5(4)$ \\
\hline Birmingham \& Solihull & $4(4)$ \\
\hline Coventry & $1(1)$ \\
\hline Shropshire, Telford \& Wrekin & $1(1)$ \\
\hline South Staffordshire & $1(1)$ \\
\hline Worcestershire & $1(1)$ \\
\hline Yorkshire and The Humber & $8(7)$ \\
\hline South Yorkshire & $5(4)$ \\
\hline
\end{tabular}


medRxiv preprint doi: https://doi.org/10.1101/2021.04.28.21256272; this version posted August 19, 2021. The copyright holder for this preprint (which was not certified by peer review) is the author/funder, who has granted medRxiv a license to display the preprint in perpetuity.

It is made available under a CC-BY-NC-ND 4.0 International license.

West Yorkshire

$3(3)$

East Midlands

$7(6)$

Leicestershire

$4(4)$

Nottinghamshire

3 (3)

South West England

6 (5)

Plymouth, Torbay \& South Devon

4 (4)

Avon

$1(1)$

Gloucestershire

$1(1)$

North East England

3 (3)

Sunderland

3 (3)

East of England

2 (2)

Cambridgeshire

$1(1)$

Norfolk

$1(1)$ 
Table 2: Concerns raised by coroners, grouped by five higher-order themes, and how often they were reported

\begin{tabular}{|c|c|c|}
\hline $\begin{array}{l}\text { Theme }(\% \text { of } \\
\text { concerns) }\end{array}$ & Concern & $\begin{array}{l}\text { No. of cases } \\
(\%)\end{array}$ \\
\hline \multirow{17}{*}{$\begin{array}{l}\text { Failure to } \\
\text { follow } \\
\text { protocols } \\
(36 \%)\end{array}$} & Failure/delay in appropriate assessments & $19(17)$ \\
\hline & Failure to monitor treatment & $15(13)$ \\
\hline & Omission of necessary treatment & $13(12)$ \\
\hline & Delayed treatment & $12(11)$ \\
\hline & Failure to review medicines & $11(10)$ \\
\hline & Failure to take a history or see the patient & $10(9)$ \\
\hline & Failure/delay in performing necessary scans & $8(7)$ \\
\hline & Failure to triage patients appropriately & $7(6)$ \\
\hline & Failure to follow recommended practices & $6(5)$ \\
\hline & Failure to follow a protocol & $6(5)$ \\
\hline & Failure to review medical records & $4(4)$ \\
\hline & Failure to implement national guidelines & $3(3)$ \\
\hline & Administration of drug in error & $1(1)$ \\
\hline & Failure to arrange supervision & $1(1)$ \\
\hline & $\begin{array}{l}\text { Inability to care for both a patient's physical and mental } \\
\text { health }\end{array}$ & $1(1)$ \\
\hline & Management of medication for care home residents & $1(1)$ \\
\hline & Medication administered despite known allergy & $1(1)$ \\
\hline \multirow{9}{*}{$\begin{array}{l}\text { Communication } \\
(22 \%)\end{array}$} & Poor communication & $28(25)$ \\
\hline & Failure to keep accurate medical records & $28(25)$ \\
\hline & $\begin{array}{l}\text { Failure to escalate deterioration in patient to the relevant } \\
\text { medical professionals }\end{array}$ & $5(4)$ \\
\hline & Failure to seek specialist advice when indicated & $4(4)$ \\
\hline & Failure to follow the advice of a senior clinician & $2(2)$ \\
\hline & Failure to warn of the consequences of not taking medication & $2(2)$ \\
\hline & $\begin{array}{l}\text { Failure to inform the patient about a medical procedure and } \\
\text { aftercare }\end{array}$ & $2(2)$ \\
\hline & Failure to warn of adverse drug reactions & $1(1)$ \\
\hline & Failure to obtain informed consent & $1(1)$ \\
\hline \multirow[t]{7}{*}{ Safety $(21 \%)$} & Poor systems & $35(31)$ \\
\hline & Discharge process & $16(14)$ \\
\hline & Non-robust investigation following the death & $15(13)$ \\
\hline & Safety of facilities & $2(2)$ \\
\hline & Nature of inspections of care homes & $1(1)$ \\
\hline & Failure to address measures identified in risk assessment & $1(1)$ \\
\hline & $\begin{array}{l}\text { Failure to make a reasonable effort to ensure patient } \\
\text { adherence }\end{array}$ & $1(1)$ \\
\hline \multirow{6}{*}{$\begin{array}{l}\text { Education and } \\
\text { training }(14 \%)\end{array}$} & Inadequate training & $12(11)$ \\
\hline & Inappropriate dosage for the patient & $9(8)$ \\
\hline & Failure to appreciate the risk (of giving/not giving a drug) & $6(5)$ \\
\hline & Lack of clinical knowledge & $5(4)$ \\
\hline & Poor clinical decision-making & $5(4)$ \\
\hline & Poor awareness of symptoms & $4(4)$ \\
\hline
\end{tabular}




\begin{tabular}{lll}
\hline & Poor awareness of rare ADRs & $2(2)$ \\
& Poor awareness of rare complications of medical procedures & $1(1)$ \\
& Failure of training & $1(1)$ \\
& Drug awareness & $1(1)$ \\
& Poor awareness of drug-drug interactions & $1(1)$ \\
& Wrong method of administration & $1(1)$ \\
\hline Resources (7\%) & Absence of national guidelines & $10(9)$ \\
& Under staffing & $7(6)$ \\
Shortage/lack of availability of appropriate medical & $3(3)$ \\
& equipment & $2(2)$ \\
& Hospital opening times/availability & $1(1)$ \\
& Unavailable drug & $1(1)$ \\
\hline
\end{tabular}


medRxiv preprint doi: https://doi.org/10.1101/2021.04.28.21256272; this version posted August 19, 2021. The copyright holder for this preprint (which was not certified by peer review) is the author/funder, who has granted medRxiv a license to display the preprint in perpetuity.

It is made available under a CC-BY-NC-ND 4.0 International license .

Table 3: Recipients of coroners Prevent Future Death reports (PFDs) and their response rates to reports

\begin{tabular}{|c|c|c|c|c|c|c|}
\hline \multirow[b]{2}{*}{ Addressee } & \multirow{2}{*}{$\begin{array}{l}\text { No. of } \\
\text { reports } \\
\text { received }\end{array}$} & \multirow{2}{*}{$\begin{array}{l}\text { No. of } \\
\text { responses }\end{array}$} & \multirow{2}{*}{$\begin{array}{c}\text { Response } \\
\text { rate }(\%)\end{array}$} & \multicolumn{3}{|c|}{ Classification of responses } \\
\hline & & & & $\begin{array}{c}\% \text { On } \\
\text { time }\end{array}$ & $\%$ Late & $\begin{array}{c}\% \\
\text { Overdue }\end{array}$ \\
\hline NHS entities & 118 & 60 & 51 & 38 & 13 & 49 \\
\hline CCGs & 3 & 3 & 100 & 67 & 33 & 0 \\
\hline NHS 111 & 1 & 1 & 100 & 100 & 0 & 0 \\
\hline NHS Wales & 1 & 1 & 100 & 100 & 0 & 0 \\
\hline $\begin{array}{l}\text { Ambulance } \\
\text { services }\end{array}$ & 7 & 5 & 71 & 57 & 14 & 29 \\
\hline NHS Trusts & 53 & 32 & 60 & 45 & 15 & 40 \\
\hline NHS England & 4 & 2 & 50 & 50 & 0 & 50 \\
\hline hospitals & 19 & 7 & 37 & 26 & 11 & 63 \\
\hline $\begin{array}{l}\text { General } \\
\text { practices }\end{array}$ & 14 & 5 & 36 & 29 & 7 & 64 \\
\hline $\begin{array}{l}\text { Local Health } \\
\text { Boards }\end{array}$ & 3 & 1 & 33 & 0 & 33 & 67 \\
\hline $\begin{array}{l}\text { University } \\
\text { Health Boards }\end{array}$ & 10 & 3 & 30 & 20 & 10 & 70 \\
\hline $\begin{array}{l}\text { Mental Health } \\
\text { Trusts }\end{array}$ & 2 & 0 & 0 & 0 & 0 & 100 \\
\hline NHS Pathways & 1 & 0 & 0 & 0 & 0 & 100 \\
\hline Government & 17 & 5 & 29 & 18 & 12 & 71 \\
\hline DHSC & 7 & 3 & 43 & 14 & 29 & 57 \\
\hline $\begin{array}{l}\text { Local } \\
\text { authorities }\end{array}$ & 3 & 1 & 33 & 33 & 0 & 67 \\
\hline $\begin{array}{l}\text { Welsh } \\
\text { Government }\end{array}$ & 7 & 1 & 14 & 14 & 0 & 86 \\
\hline $\begin{array}{l}\text { Professional } \\
\text { bodies }\end{array}$ & 21 & 4 & 19 & 10 & 10 & 81 \\
\hline CQC & 6 & 2 & 33 & 17 & 17 & 67 \\
\hline NICE & 8 & 2 & 25 & 13 & 13 & 75 \\
\hline GMC & 2 & 0 & 0 & 0 & 0 & 100 \\
\hline BMA & 1 & 0 & 0 & 0 & 0 & 100 \\
\hline GDC & 1 & 0 & 0 & 0 & 0 & 100 \\
\hline MHRA & 1 & 0 & 0 & 0 & 0 & 100 \\
\hline AACE & 1 & 0 & 0 & 0 & 0 & 100 \\
\hline $\begin{array}{l}\text { The Renal } \\
\text { Association }\end{array}$ & 1 & 0 & 0 & 0 & 0 & 100 \\
\hline Others & 18 & 3 & 17 & 11 & 6 & 83 \\
\hline Police & 1 & 1 & 100 & 0 & 100 & 0 \\
\hline $\begin{array}{l}\text { Private } \\
\text { companies }\end{array}$ & 4 & 1 & 25 & 25 & 0 & 75 \\
\hline Care homes & 9 & 1 & 11 & 11 & 0 & 89 \\
\hline
\end{tabular}


medRxiv preprint doi: https://doi.org/10.1101/2021.04.28.21256272; this version posted August 19, 2021. The copyright holder for this preprint (which was not certified by peer review) is the author/funder, who has granted medRxiv a license to display the preprint in perpetuity.

It is made available under a CC-BY-NC-ND 4.0 International license.

\begin{tabular}{|c|c|c|c|c|c|c|}
\hline Carewatch & 1 & 0 & 0 & 0 & 0 & 100 \\
\hline $\begin{array}{l}\text { Highway } \\
\text { maintenance }\end{array}$ & 1 & 0 & 0 & 0 & 0 & 100 \\
\hline $\begin{array}{l}\text { Housing } \\
\text { Associations }\end{array}$ & 1 & 0 & 0 & 0 & 0 & 100 \\
\hline Local Charities & 1 & 0 & 0 & 0 & 0 & 100 \\
\hline Medical societies & 4 & 0 & $\mathbf{0}$ & 0 & $\mathbf{0}$ & 100 \\
\hline BCS & 1 & 0 & 0 & 0 & 0 & 100 \\
\hline BRS & 1 & 0 & 0 & 0 & 0 & 100 \\
\hline ICS & 1 & 0 & 0 & 0 & 0 & 100 \\
\hline RPS & 1 & 0 & 0 & 0 & 0 & 100 \\
\hline $\begin{array}{l}\text { Medical royal } \\
\text { colleges }\end{array}$ & 3 & $\mathbf{0}$ & $\mathbf{0}$ & $\mathbf{0}$ & $\mathbf{0}$ & 100 \\
\hline RCGP & 1 & 0 & 0 & 0 & 0 & 100 \\
\hline RCOG & 1 & 0 & 0 & 0 & 0 & 100 \\
\hline $\mathrm{RCP}$ & 1 & 0 & 0 & 0 & 0 & 100 \\
\hline Total & 181 & 72 & 40 & 29 & 11 & 60 \\
\hline \multicolumn{7}{|c|}{$\begin{array}{l}\text { AACE: Association of Ambulance Chief Executives; BCS: British Cardiovascular Society; BMA: British } \\
\text { Medical Association; BRS: British Renal Society; CQC: Care Quality Commission; DHSC: Department of } \\
\text { Health and Social Care; GDC: General Dental Council; GMC: General Medical Council; ICS: Intensive } \\
\text { Care Society; MHRA: Medicines and Healthcare products Regulatory Agency; NICE: The National } \\
\text { Institute for Health and Care Excellence; NHS: National Health Service; RCGP: Royal College of General } \\
\text { Practitioners; RCOG: Royal College of Obstetricians and Gynaecologists; RCP: Royal College of } \\
\text { Physicians; RPS: Royal Pharmaceutical Society }\end{array}$} \\
\hline
\end{tabular}




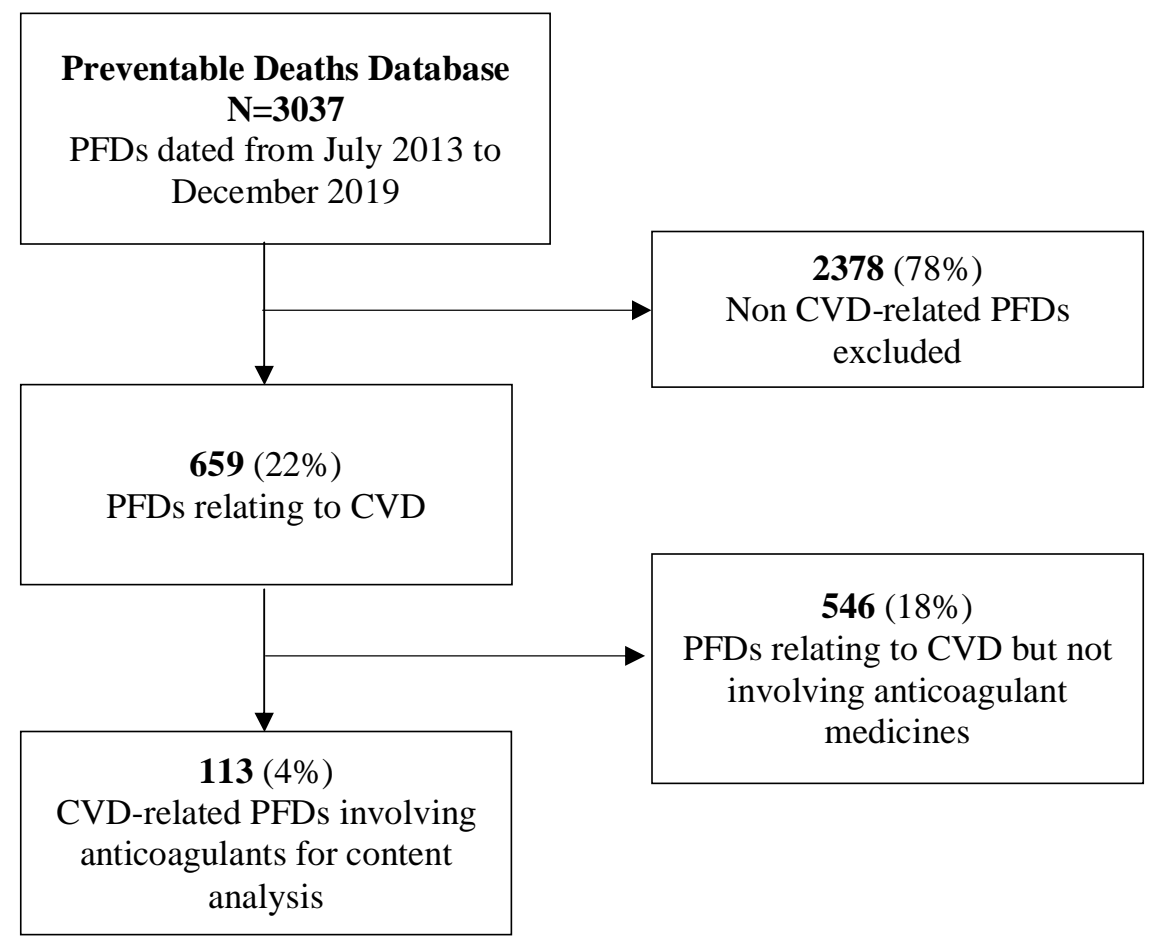

Figure 1: Flow diagram showing the numbers of Prevent Future Death reports (PFDs) included and excluded from the Preventable Deaths Database using the eligibility criteria for this study 
medRxiv preprint doi: https://doi.org/10.1101/2021.04.28.21256272; this version posted August 19, 2021. The copyright holder for this preprint (which was not certified by peer review) is the author/funder, who has granted medRxiv a license to display the preprint in perpetuity.

It is made available under a CC-BY-NC-ND 4.0 International license .

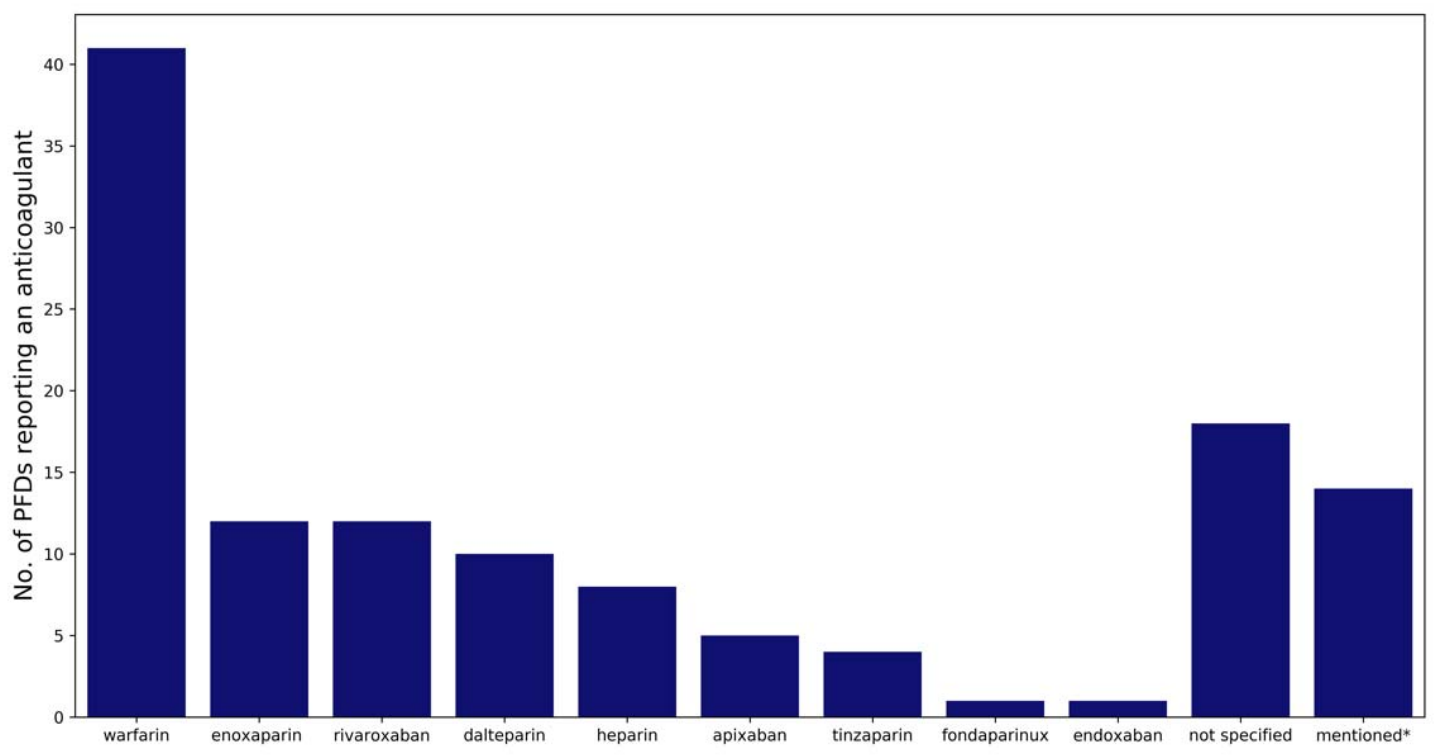

Figure 2: Anticoagulants reported in cardiovascular disease-related Prevent Future Death reports (PFDs). *in these PFDs, the coroner suggested that if an anticoagulant had been used the death might have been prevented 